\section{GESTIÓN DEL CAPITAL DE TRABAJO: ANÁLISIS DESCRIPTIVO Y CORRELACIONAL PARA EMPRESAS ARGENTINAS COTIZANTES EN BOLSA}

\author{
MANAGEMENT OF WORKING CAPITAL: \\ DESCRIPTIVE AND CORRELATIONAL ANALYSIS \\ FOR ARGENTINE COMPANIES IN THE STOCK MARKET
}

María Alicia Schimdt | Gastón Milanesi

\section{RESUMEN}

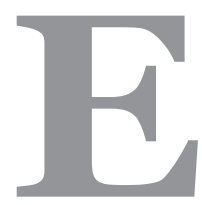
xiste amplia literatura sobre la gestión del capital de trabajo, i.e., las relaciones e interdependencias entre sus componentes individuales y la influencia en el desempeño corporativo. El objetivo del presente trabajo es realizar un análisis estadístico descriptivo y correlacional bivariado sobre una serie de variables aplicables a empresas argentinas cotizantes en bolsa, para el rango temporal de análisis 2009-2018. Los resultados más relevantes que surgen de la investigación muestran la existencia de una fuerte relación directa entre el tamaño y el endeudamiento de las firmas; y una fuerte vinculación inversa entre el tamaño y el ciclo operativo de las mismas.

Palabras clave: capital de trabajo, gestión del capital de trabajo, empresas argentinas cotizantes en bolsa.

\begin{abstract}
There is ample literature on the management of working capital, i.e., the relationships and interdependencies between its individual components and the influence on corporate performance. The objective of this paper is to perform a bivariate descriptive and correlational statistical analysis on a series of variables applicable to Argentine listed companies on the stock exchange, for the 2009-2018 timeframe of analysis. The most relevant results that emerge from the investigation show the existence of a strong direct relationship between the size and the indebtedness of the firms and a strong inverse link between the size and the operating cycle of the same.
\end{abstract}

Keywords: working capital, working capital management, argentine companies listed on the stock exchange.
María Alicia Schimdt alicia.schmidt@uns.edu.ar

Gastón Milanesi milanesi@uns.edu.ar

Departamento de Ciencias de la Administración

Universidad Nacional del Sur ARGENTINA

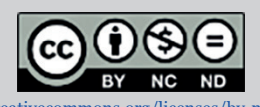

https://creativecommons.org/licenses/by-nc-nd/4.0/ Revista de la Facultad de Ciencias Económicas ISSN 1668-6357 (formato impreso) ISSN 1668-6365 (formato digital) por Facultad de Ciencias Económicas Universidad Nacional del Nordeste (UNNE) Argentina se distribuye bajo una Licencia Creative Commons Atribución - No Comercial - Sin Obra Derivada 4.0 Internacional. 


\section{INTRODUCCIÓN}

Existe amplia literatura sobre la gestión del capital de trabajo y las relaciones e interdependencia entre los componentes individuales del mismo, al momento de evaluar su influencia en el desempeño corporativo. Tal como indican Baños-Caballero, García-Teruel, \& Martínez-Solano (2014), escasos estudios revelan evidencia empírica sobre los efectos que tiene la inversión en capital de trabajo en el rendimiento o desempeño corporativo de una compañía. Diversos autores exponen que existe una relación inversa entre inversión en capital de trabajo y rendimiento de la compañía (Smith, 1980; Shin \& Soenen, 1998; Wang, 2002; Deloof, 2003; Padachi, 2006; Raheman \& Nasr, 2007; Garcia-Teruel \& Martínez-Solano, 2007; Akinlo, 2010); mientras que algunos de ellos asi mismo manifiestan paralelamente lo contrario (Smith, 1980; Deloof, 2003).

Cabe mencionar entender la gestión del capital de trabajo implica necesario comprender cómo se comporta el capital de trabajo y su impacto en la rentabilidad de la compañía, desde una óptica de política conservadora y desde una visión de política agresiva, siendo que ambas pueden causar resultados negativos y con esto una pérdida o destrucción del valor en la riqueza de los propietarios. Autores como Deloof (2003), Baños-Caballero, García-Teruel, \& Martínez-Solano (2012, 2014), entre otros, entienden y explican que existe un nivel óptimo de capital de trabajo y de ciclo de conversión de efectivo al cual la empresa puede llegar. Esto se desarrolla ampliamente desde el aspecto teórico mediante una revisión de la literatura al respecto.

El trabajo que realizan Baños-Caballero et al. (2014), contribuye a la bibliografía científica sobre gestión de capital de trabajo de una forma innovadora, dado que ofrecen nueva evidencia sobre el efecto de la gestión del capital de trabajo en el en el rendimiento (desempeño) corporativo, a través de relaciones no linealidades. Los mencionado investigadores plantean en su artículo la existencia de un nivel óptimo de inversión en capital de trabajo en el cual el rendimiento o desempeño empresario es el máximo logrado. Este aporte es importante para conocer cuál es ese nivel óptimo y así obtener el mayor desempeño corporativo como así también para lograr una adecuada planificación financiera, particularmente en determinados casos en los que se carece de una gestión de la rotación de las cuentas por cobrar y pagar, e inventarios, i.e. la gestión del capital de trabajo, provocando descalces financieros, debilitando y ahogando a las empresas.

Los investigadores realizan el planteo explicado mediante la construcción de un modelo de regresión múltiple no lineal de tipo cóncava. Ellos proponen una serie de variables como determinantes del desempeño corporativo.

El objetivo del presente trabajo es realizar un análisis estadístico descriptivo y correlacional bivariado con las variables que formulan Baños-Caballero et al. (2014) en su estudio, para caracterizar a la unidad de análisis objeto de investigación que son las empresas argentinas cotizantes en bolsa, para el rango temporal de análisis 2009-2018. 
Como se expresa, estos autores sugieren una serie de variables las cuales son tomadas aquí como variables de entrada o input para realizar un estudio previo descriptivo y correlacional, y observar y explicar cuáles se encuentran correlacionadas con mayor intensidad y en qué dirección.

Este trabajo se presenta como fase previa de una investigación más amplia en la que se busca replicar el citado modelo de regresión múltiple no lineal de tipo cóncava con la innovación de inyectar una variable adicional al modelo que es la probabilidad de insolvencia o default financiero y observar cómo se comporta tal modelo.

\section{MARCO TEÓRICO}

\subsection{Gestión del capital de trabajo}

De la revisión de la literatura existente surgen diferentes posturas o enfoques sobre la inversión en capital de trabajo y el desempeño o rendimiento corporativo. Investigadores como Smith (1980); Jose, Lancaster, \& Stevens (1996); Shin \& Soenen (1998); Wang (2002); Deloof (2003); Faulkender \& Wang (2006); Padachi (2006); Raheman \& Nasr (2007); Garcia-Teruel \& Martínez-Solano (2007); Akinlo (2010) y Kieschnick, Laplante, \& Moussawi (2013), entre otros, demuestran evidencia empírica de una relación inversa entre inversión en capital de trabajo (medido este en magnitud monetaria o magnitud de tiempo) y rendimiento de rentabilidad o desempeño de una firma. Asimismo, algunos de los mencionados autores expresan lo contrario, tal es el caso de Smith (1980); y Deloof (2003), quienes en sus estudios revelan del mismo modo la presencia de una vinculación directa entre capital de trabajo y el desempeño corporativo. Gill, Biger, \& Mathur (2010); Nobanee \& Alhajjar (2014) presenta en sus trabajos resultados que arrojan evidencia de una relación positiva observada entre el Ciclo de Conversión de Efectivo y la rentabilidad de la firma.

Por otra parte, existe evidencia empírica de una relación no lineal entre la inversión en capital de trabajo y el rendimiento de una firma. Lazaridis \& Tryfonidis (2006). Afza \& Nazir (2007); Nobanee \& Alhajjar (2009) y Nobanee \& Alhajjar (2014); Akinlo (2010) y BañosCaballero, García-Teruel, \& Martínez-Solano (2012, 2014), exponen la existencia de un nivel óptimo de inversión en capital de trabajo.

\subsection{Variables de análisis}

De acuerdo a lo expresado en la subsección anterior, Baños-Caballero et al. (2014) utilizan un modelo de regresión múltiple que construyen a partir de variables o input explicativas del desempeño (performance) empresaria. Se expone en la Tabla 1 la simbología de cada variable, su nombre y la definición y los parámetros de construcción de las variables (variable de- 
pendiente: Desempeño Corporativo; variables independientes: Ciclo Financiero Neto o Ciclo Comercial Neto, Tamaño de la Firma, Endeudamiento, Crecimiento y ROA).

Tabla 1. Definiciones para cálculo de Variables según trabajo publicado de Baños-Caballero, García-Teruel, \& Martínez-Solano (2014), pp. 334-335.

\begin{tabular}{|c|c|c|c|}
\hline Variable & Nombre & Definición / Parámetros de Construcción \\
\hline $\mathbf{Q}_{\text {(it) }}$ & $\begin{array}{c}\text { Desempeño (Performance) } \\
\text { Corporativo (de una firma } \boldsymbol{i} \text {, en } \\
\text { un momento } \boldsymbol{t} \text { ) }\end{array}$ & $\begin{array}{c}\text { Es la relación entre la suma del valor de mercado } \\
\text { del capital y el valor contable de la deuda con el valor en libros } \\
\text { de los activos. }\end{array}$ \\
\hline NTC & $\begin{array}{c}\text { Ciclo Comercial Neto de la } \\
\text { Firma (o también llamado Ciclo } \\
\text { Financiero, representa una } \\
\text { magnitud de tiempo) }\end{array}$ & $\begin{array}{c}\text { Los autores utilizan esta métrica como una medida para } \\
\text { cuantificar la administración del capital de trabajo. } \\
\text { Su forma de cálculo está dada por lo siguiente: NTC }= \\
\text { (cuentas por cobrar / ventas) * } 365+\text { inventarios / ventas) } \\
{ }^{*} 365-\text { (cuentas por pagar/ventas) * } 365 .\end{array}$ \\
\hline SIZE & Tamaño de la Firma & $\begin{array}{c}\text { Se calcula como el logaritmo natural de las ventas. } \\
\text { LEV }\end{array}$ & $\begin{array}{c}\text { Endeudamiento de la Firma } \\
\text { Se calcula por la relación entre la deuda total } \\
\text { y los activos totales. }\end{array}$ \\
\hline ROA & $\begin{array}{c}\text { Oportunidad de Crecimiento de } \\
\text { la Firma }\end{array}$ & $\begin{array}{c}\text { Se calcula como la relación valor en libros de los activos } \\
\text { intangibles sobre activos totales. }\end{array}$ \\
\hline
\end{tabular}

Fuente: elaboración propia, (2018).

Específicamente, para el desarrollo del presente trabajo, se utilizan tales variables presentadas (Baños-Caballero et al., 2014) para el análisis estadístico descriptivo y el análisis correlacional bivariado, como forma de caracterización de la unidad de análisis.

\subsection{Variable agregada: Probabilidad de insolvencia}

Asimismo se inyecta en el análisis descriptivo y correlacional, la probabilidad de insolvencia o fracaso financiero. La misma se define a partir del Modelo Naive el cual es desarrollado por Bharath y Shumway (2008).

\section{METODOLOGÍA}

En el presente trabajo de investigación la unidad de análisis está conformada por empresas argentinas cotizantes en Bolsa, correspondiente al último decenio tomado como rango temporal del análisis, i.e. 2009-2018. Dada la asimetría espacial creada en la matriz de datos se decide la exclusión de aquellas empresas cuyos datos sean inexistentes para algún ejercicio del período 2009-2018. De la unidad de análisis relevada, surge un total de 57 empresas cotizantes argentinas que la integran. Se ha completado el relevamiento de datos duros de los Estados Financieros 
Individuales (o también denominados Estados Financieros por Separados) de las empresas que conforman la unidad de análisis. Los datos duros obtenidos corresponden a los Estados Financieros presentados y publicados en el sitio web institucional de la Comisión Nacional de Valores y en el sitio web Bolsar (C) correspondiente a la Bolsa de Comercio de Buenos Aires. Estos datos duros son el input para la construcción de las variables expuestas en la Tabla 1 de la sección anterior. A continuación se expone el tipo de estudio que se realiza sobre la unidad de análisis objeto de estudio.

Con motivo de sectorizar a la unidad de análisis, se utilizaron como vectores de clasificación el Tamaño de la firma y el Endeudamiento de la firma. De esta forma quedan definidos dos grupos de análisis para según cada vector, i.e. compañías que se ubiquen como aquellas de mayor tamaño (por encima del tamaño promedio ponderado) y compañías que se sitúen como de menor tamaño (por debajo del promedio ponderado). Lo mismo ocurre para el caso del endeudamiento, se tienen dos grupos de análisis, aquellas empresas con mayor endeudamiento (por debajo del promedio ponderado) y aquellas con menor endeudamiento (por debajo del promedio ponderado). Se utilizan estos vectores de clasificación dada la significatividad y representatividad de los mismos para sectorización de la unidad de análisis. Para realizar el cálculo del grado de endeudamiento promedio y el tamaño promedio se determinó y aplico promedios ponderados utilizando la capitalización bursátil de las firmas.

Asimismo se realiza un análisis correlacional bivariado entre todas las variables presentadas en la sección anterior, para cada año del rango temporal de estudio. Cabe destacar que al realizar el estudio de correlación se utilizaron dos software, Excel@) y SPSSC (Statistical Package for the Social Sciences(C). El coeficiente empleado para determinar la intensidad de la correlación bivariada es el indicador de Pearson, el cual refleja la linealidad de la relación. Hernández Sampieri, Fernández Collado, \& Baptista (p. 305, 2014) presentan una jerarquía tabulada de interpretación del grado de intensidad que arroje el coeficiente de Pearson como resultado de la correlación. Asimismo, se contempla un nivel de significancia del $5 \%$, y un nivel de significancia muy alta del $1 \%$.

Las variables que se emplean para realizar el análisis estadístico descriptivo comparado entre carteras y el análisis correlacional bivariado, son las que se presentan en el artículo de Baños-Caballero et al. (2014) que fueron comentadas en la sección precedente. Cabe destacar que para determinar el endeudamiento de la firma, no se sigue la forma de cálculo allí expuesta, sino que se optó por utilizar la función logarítmica (logaritmo natural del pasivo), tal como se aplica para calcular el tamaño de la empresa (logaritmo natural de las ventas). Asimismo, se incorpora al análisis la variable Ciclo Operativo (mismo cálculo que para el Ciclo Comercial Neto -NTC- solo que tiene en los días de conversión de las cuentas las cuentas a cobrar y los días de conversión de inventarios). Por otra parte, también se incluye en el análisis una variable adicional, i.e. las probabilidades de insolvencia para cada empresa en cada año 
del período de estudio. Se aclara que en el presente trabajo, para nombrar a la variable Ciclo Comercial Neto o Ciclo Financiero (NTC) y las Oportunidades de Crecimiento (GROWTH), se deja la misma nominación en idioma inglés, tal como está expresada en el documento de Baños-Caballero et al. (2014).

\section{RESULTADOS}

\subsection{Estadística descriptiva comparativa}

En esta sección se presenta un análisis estadístico descriptivo particular comparativo que incluye 570 observaciones, realizadas durante 10 años (2009-2018) para 57 firmas argentinas cotizantes en Bolsa.

La Tabla 2 muestra la estadística descriptiva de todas las variables analizadas para el conjunto o grupo de compañías que integran la Cartera 1, i.e. aquellas cuyo tamaño se ubica por encima del tamaño promedio (cartera compuesta por firmas de mayor tamaño), y para las firmas que nuclean la Cartera 2 i.e. aquellas empresas cuyo tamaño se encuentra por debajo del tamaño promedio (cartera compuesta por firmas de menor tamaño). Para la Cartera 1 se totalizan 27 observaciones realizadas que corresponden a las firmas que registraron un tamaño superior al promedio; y para la Cartera 2 se registran 543 observaciones efectuadas las cuales pertenecen a las firmas que poseen un tamaño inferior al promedio, quedando así contabilizadas 570 observaciones que pertenecen a las 57 empresas durante el transcurso del decenio 2009-2018.

Tabla 2. Estadística Descriptiva de Carteras

(Vector de Clasificación de Carteras: Tamaño). Período 2009-2018.

\begin{tabular}{|c|c|c|c|c|c|c|}
\cline { 2 - 7 } \multicolumn{1}{c|}{} & \multicolumn{6}{c|}{ Cartera 1 (Firmas con Tamaño superior a la Media) } \\
\hline $\begin{array}{c}\text { Estadísticos } \\
\text { Descriptivos }\end{array}$ & $\mathrm{Q}_{i, t}$ & $\begin{array}{c}\text { NTC (Ciclo } \\
\text { Financiero) }\end{array}$ & $\begin{array}{c}\text { Ciclo } \\
\text { Operativo }\end{array}$ & GROWTH & ROA & p (n=10) \\
\hline Media & $\mathbf{1 , 6 9}$ & $\mathbf{6 2}$ & $\mathbf{1 1 0}$ & $\mathbf{0 , 0 9}$ & $\mathbf{0 , 1}$ & $\mathbf{1 1 , 2 1 \%}$ \\
\hline Desvío & $\mathbf{0 , 2 9}$ & $\mathbf{7 1}$ & $\mathbf{5 8}$ & $\mathbf{0 , 0 8}$ & $\mathbf{o , 0 3}$ & $\mathbf{8 , 9 3 \%}$ \\
\hline Observaciones & $\mathbf{2 7}$ & $\mathbf{2 7}$ & $\mathbf{2 7}$ & $\mathbf{2 7}$ & $\mathbf{2 7}$ & $\mathbf{2 7}$ \\
\hline & \multicolumn{7}{|c|}{ Cartera 2 (Firmas con Tamaño inferior a la Media) } \\
\hline $\begin{array}{c}\text { Estadísticos } \\
\text { Descriptivos }\end{array}$ & $\mathrm{Q}_{i, t}$ & $\begin{array}{c}\text { NTC (Ciclo } \\
\text { Financiero) }\end{array}$ & $\begin{array}{c}\text { Ciclo } \\
\text { Operativo }\end{array}$ & GROWTH & ROA & $\mathrm{p}(\mathrm{n}=10)$ \\
\hline Media & $\mathbf{1 , 5 2}$ & $\mathbf{8 1}$ & $\mathbf{1 5 7}$ & $\mathbf{0 , 0 3}$ & $\mathbf{0 , 0 8}$ & $\mathbf{1 9 , 4 5 \%}$ \\
\hline Desvío & $\mathbf{0 , 6 5}$ & $\mathbf{9 0}$ & $\mathbf{1 0 7}$ & $\mathbf{0 , 1 1}$ & $\mathbf{0 , 1 3}$ & $\mathbf{2 5 , 4 3 \%}$ \\
\hline Observaciones & $\mathbf{5 4 3}$ & $\mathbf{5 4 3}$ & $\mathbf{5 4 3}$ & $\mathbf{5 4 3}$ & $\mathbf{5 4 3}$ & $\mathbf{5 4 3}$ \\
\hline
\end{tabular}

Fuente: elaboración propia, (2018). 
De igual modo se expone la Tabla 3, que arroja los resultados de la estadística descriptiva de todas las variables analizadas para el conjunto o grupo de compañías que integran la Cartera 1, i.e. aquellas cuyo endeudamiento se ubica por encima del endeudamiento promedio (cartera compuesta por firmas de mayor endeudamiento), y para las firmas que componen la Cartera 2 i.e. aquellas empresas cuyo endeudamiento se encuentra por debajo del endeudamiento promedio (cartera compuesta por firmas de menor endeudamiento). Para la Cartera 1 se totalizan 28 observaciones realizadas (empresas que registran un nivel de endeudamiento superior al promedio de deuda) y para la Cartera 2 se registran 542 observaciones efectuadas (aquí se ubican las firmas que se encuentran con un nivel de endeudamiento inferior al nivel promedio de deuda), quedando así contabilizadas 570 observaciones que pertenecen a las 57 empresas durante el transcurso del decenio 2009-2018.

Tabla 2. Estadística Descriptiva de Carteras

(Vector de Clasificación de Carteras: Tamaño). Período 2009-2018.

\begin{tabular}{|c|c|c|c|c|c|c|}
\cline { 2 - 7 } \multicolumn{1}{c|}{} & \multicolumn{6}{c|}{ Cartera 1 (Firmas con Endeudamiento superior a la Media) } \\
\hline $\begin{array}{c}\text { Estadísticos } \\
\text { Descriptivos }\end{array}$ & $\mathrm{Q}_{i, t}$ & $\begin{array}{c}\text { NTC (Ciclo } \\
\text { Financiero) }\end{array}$ & $\begin{array}{c}\text { Ciclo } \\
\text { Operativo }\end{array}$ & GROWTH & ROA & $\mathrm{p}(\mathrm{n}=10)$ \\
\hline Media & $\mathbf{1 , 7 1}$ & $\mathbf{6 6}$ & $\mathbf{1 2 5}$ & $\mathbf{0 , 0 9}$ & $\mathbf{0 , 1}$ & $\mathbf{1 3 , 5 2 \%}$ \\
\hline Desvío & $\mathbf{0 , 2 9}$ & $\mathbf{7 4}$ & $\mathbf{6 7}$ & $\mathbf{0 , 0 8}$ & $\mathbf{0 , 0 3}$ & $\mathbf{8 , 8 5 \%}$ \\
\hline Observaciones & $\mathbf{2 8}$ & $\mathbf{2 8}$ & $\mathbf{2 8}$ & $\mathbf{2 8}$ & $\mathbf{2 8}$ & $\mathbf{2 8}$ \\
\hline & \multicolumn{7}{|c|}{ Cartera 2 (Firmas con Endeudamiento inferior a la Media) } \\
\hline $\begin{array}{c}\text { Estadísticos } \\
\text { Descriptivos }\end{array}$ & $\mathrm{Q}_{i, t}$ & $\begin{array}{c}\text { NTC (Ciclo } \\
\text { Financiero) }\end{array}$ & $\begin{array}{c}\text { Ciclo } \\
\text { Operativo }\end{array}$ & GROWTH & ROA & $\mathrm{p}$ (n=10) \\
\hline Media & $\mathbf{1 , 5 2}$ & $\mathbf{7 9}$ & $\mathbf{1 5 5}$ & $\mathbf{0 , 0 3}$ & $\mathbf{0 , 0 8}$ & $\mathbf{1 9 , 2 3 \%}$ \\
\hline Desvío & $\mathbf{0 , 6 5}$ & $\mathbf{6 6}$ & $\mathbf{1 0 7}$ & $\mathbf{0 , 1 1}$ & $\mathbf{0 , 1 3}$ & $\mathbf{2 5 , 3 9 \%}$ \\
\hline Observaciones & $\mathbf{5 4 2}$ & $\mathbf{5 4 2}$ & $\mathbf{5 4 2}$ & $\mathbf{5 4 2}$ & $\mathbf{5 4 2}$ & $\mathbf{5 4 2}$ \\
\hline
\end{tabular}

Fuente: elaboración propia, (2018).

Como se exhibe en ambas tablas, todas las variables tienen una media positiva. Además, las estadísticas medias producen algunos resultados importantes. En primer lugar, la media del índice de desempeño corporativo manifiesta que para las empresas de menor tamaño el indicador es levemente inferior a las de mayor tamaño en un 10\%, mostrando una relación inversa. De la misma forma ocurre cuando se clasifica a las firmas a través de su grado de endeudamiento. Las de menor endeudamiento presentan un indicador medio de desempeño corporativo menor en $11 \%$ que las de mayor endeudamiento. Ambas situaciones son representadas en el Gráfico 1. 
Gráfico 1. Estadístico Descriptivo: Media del Indicador $\mathbf{Q}_{\mathrm{it}}$. Comparativo de Carteras. Período 20o9-2018.

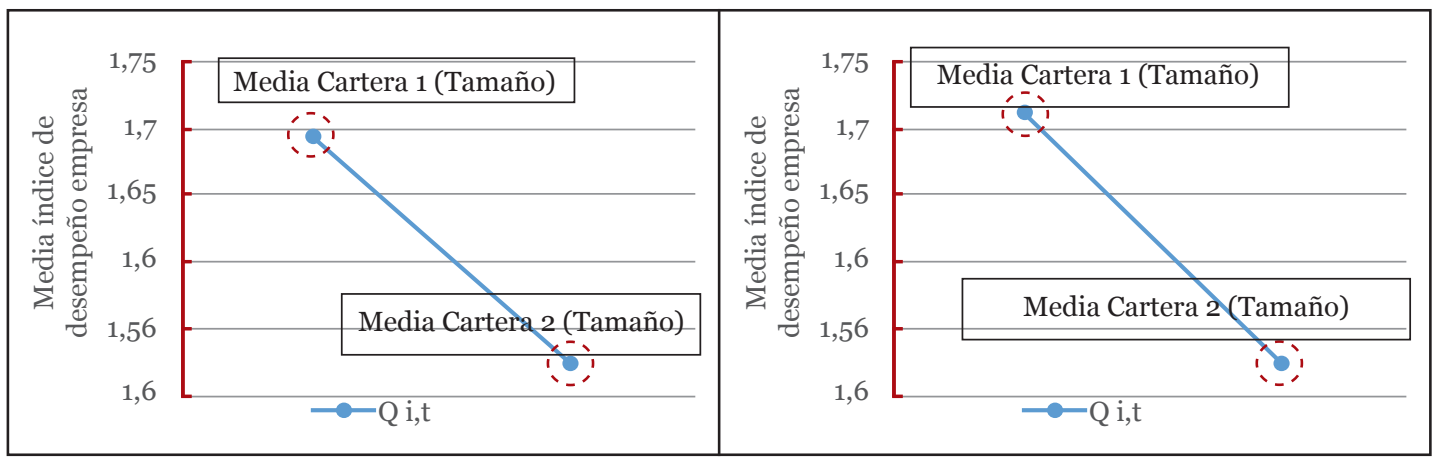

Fuente: Elaboración propia, (2019).

Con respecto a la media del ciclo financiero en días (NTC), se observa que las empresas de mayor tamaño (Cartera 1) poseen un ciclo financiero menor a las empresas de menor tamaño (Cartera 2), en un 23\%. Lo mismo ocurre con la media del ciclo operativo en días, la Cartera 1 detenta un ciclo operativo menor que la Cartera 2 en un 30\%. La misma preferencia ocurre cuando se clasifica y analiza de acuerdo al vector de endeudamiento. Para aquella Cartera comprendida por firmas de mayor endeudamiento, se visualiza que las empresas de mayor endeudamiento (Cartera 1) poseen un ciclo financiero menor a las empresas de menor endeudamiento (Cartera 2), en un 16\%. Lo mismo ocurre con la media del ciclo operativo en días, la Cartera 1 tiene un ciclo operativo menor que la Cartera 2 en un 19\%. El Gráfico 2 que se expone a continuación representa esta comparación entre carteras.

Gráfico 2. Estadístico Descriptivo: Media de los Indicadores Ciclo Financiero y Ciclo Operativo. Comparativo de Carteras. Período 2oo9-2018.

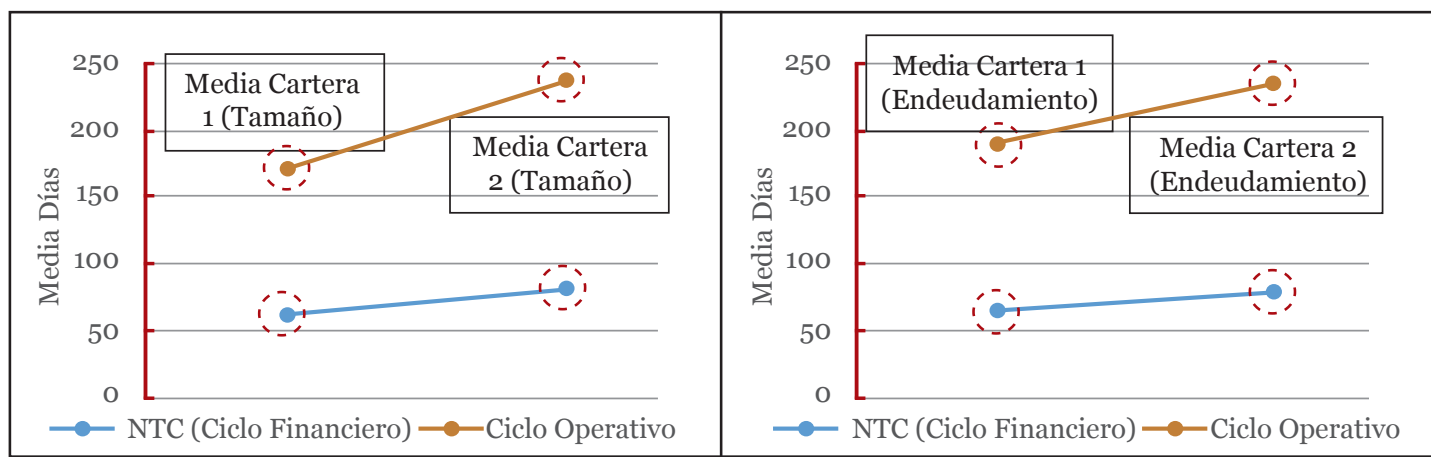

Fuente: Elaboración propia, (2019).

En relación al crecimiento (GROWTH) y ROA promedio, de acuerdo al agrupamiento por tamaño, la Cartera 1 presenta un mayor crecimiento y ROA que la Cartera 2, en un 200\% y 25\% 
respectivamente. Exactamente igual guarismo presenta las carteras clasificadas de acuerdo al endeudamiento. Esta situación comparada se muestra en las tablas precedentes y en el gráfico que sigue a continuación.

Gráfico 3. Estadístico Descriptivo: Media de los Indicadores Crecimiento y ROA. Comparativo de Carteras. Período 20o9-2018.

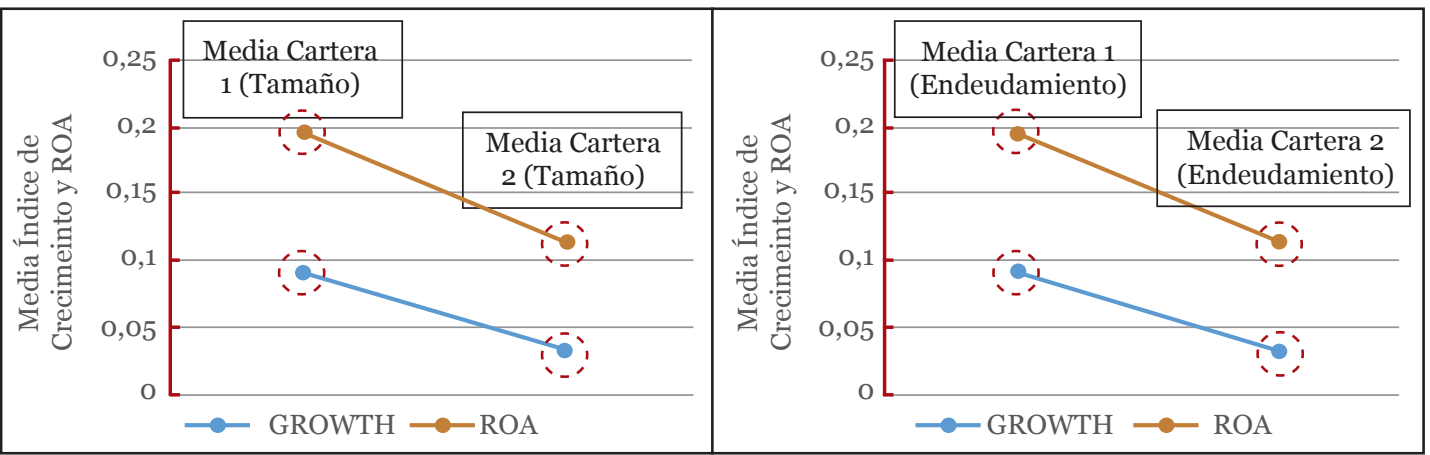

Fuente: Elaboración propia, (2019).

Finalmente, al analizar la media de las probabilidades de fracaso financiero con horizonte temporal 10 años $(\mathrm{n}=10)$, aquellas compañías de mayor tamaño (Cartera 1) indican una menor probabilidad de insolvencia que las firmas de menor tamaño (Cartera 2), en un $42 \%$. Del mismo modo, de acuerdo al grado de endeudamiento, la Cartera 1 presenta menor probabilidad de insolvencia que la Cartera 2, en un 30\%. Las Carteras clasificadas de acuerdo al tamaño y endeudamiento siguen la misma tendencia pero las probabilidades de default son más altas cuando en el caso de las compañías ubicadas por encima del endeudamiento promedio (Cartera 1). Esto se grafica a continuación.

Gráfico 4. Estadístico Descriptivo: Media de Probabilidad de Insolvencia. Comparativo de Carteras. Período 2oo9-2018.

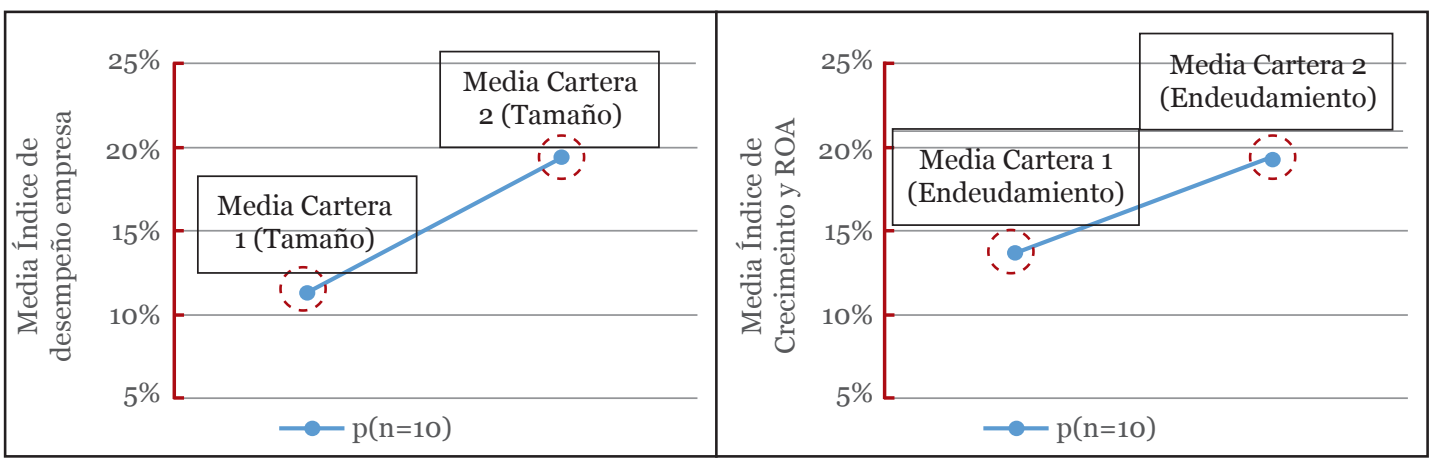

Fuente: Elaboración propia, (2019). 
En cuanto al desvío estándar o dispersión de datos con respecto a su valor medio, los mismos son más acentuados en la Cartera 2, i.e., se registra una mayor dispersión de datos con respecto a la media, en la Cartera 2, tanto cuando se clasifican por tamaño y por endeudamiento.

Para concluir con los resultados que arroja la estadística descriptiva para las carteras, es importante señalar que la conformación de la Cartera 1 clasificada por Tamaño (comprendiendo a las empresas de mayor tamaño), queda integrada a partir de 2014 solo con las firmas YPF y Tenaris en ese orden. Esto es congruente con los valores absolutos observados del Balance de cada una de ellas, correspondiendo también a los máximos valores absolutos de Ventas en ese orden (recordar que el indicador de tamaño de las firmas con el cual se realizó la clasificación de carteras, está dado por el logaritmo natural de las ventas). Lo mismo ocurre para la integración de la Carteta 1 clasificada por Endeudamiento (comprendiendo a las empresas de mayor endeudamiento), la cual se presenta constituida a partir de 2014 solo con las firmas YPF y Tenaris también en ese orden. Asimismo, existe una correspondencia con los valores absolutos extraídos del Balance de cada una de estas empresas, concerniendo también a los máximos valores absolutos de Pasivo en ese orden (recordar que el indicador de endeudamiento de las firmas con el cual se realizó la clasificación de carteras, está dado por el logaritmo natural del pasivo declarado según Balance).

\subsection{Correlaciones bivariadas}

A continuación se explican y grafican los resultados que arrojan las correlaciones más relevantes, aquellas cuya correlación registra un indicador de Pearson de rango de intensidad entre media a fuerte. Las mismas se exhiben de forma completa en el Anexo I de este documento.

Al analizar la vinculación entre el Tamaño y el Endeudamiento de las firmas, se observa una correlación con dirección positiva muy fuerte en todos los años del período de estudio, i.e. 2009-2018. Como se muestra en el gráfico que sigue, existe una caída del indicador de correlación para el año 2011 llegando a 0,81 puntos, lo que aún representa una correlación considerable. Por otra parte, en 2018 alcanza su valor más elevado, llegando a una correspondencia positiva muy fuerte de 0,90 aproximadamente. Esto demuestra que las empresas de mayor tamaño poseen mayor capacidad de absorción de deuda para financiar su crecimiento. Se observa luego que para las relaciones bivariadas entre Endeudamiento y Crecimiento y entre Tamaño y Crecimiento, existe una correlación positiva alta. Esto significa que cuando se incrementa el tamaño de una firma, en igual dirección lo harían el Endeudamiento (en una intensidad fuerte) y el crecimiento (en una intensidad media). En promedio, para tal rango temporal bajo análisis, se tiene un índice de Pearson de o,88. Esto significa, para todos los años, que existe una fuerte dependencia o correlación estocástica con tendencia lineal directa, puesto que al incrementarse el Endeudamiento de la firma, también lo hace su Tamaño. Cabe destacar que se obtiene un alto nivel de significancia bilateral de $\mathrm{p}<1 \%$, lo que representa que la correlación es estadísticamente significativa, i.e. el riesgo de concluir que existe una correlación positiva fuerte cuando en realidad no es así, es menor al $1 \%$. 
Gráfico 5. Correlación Tamaño-Endeudamiento. Período 2009-2018.

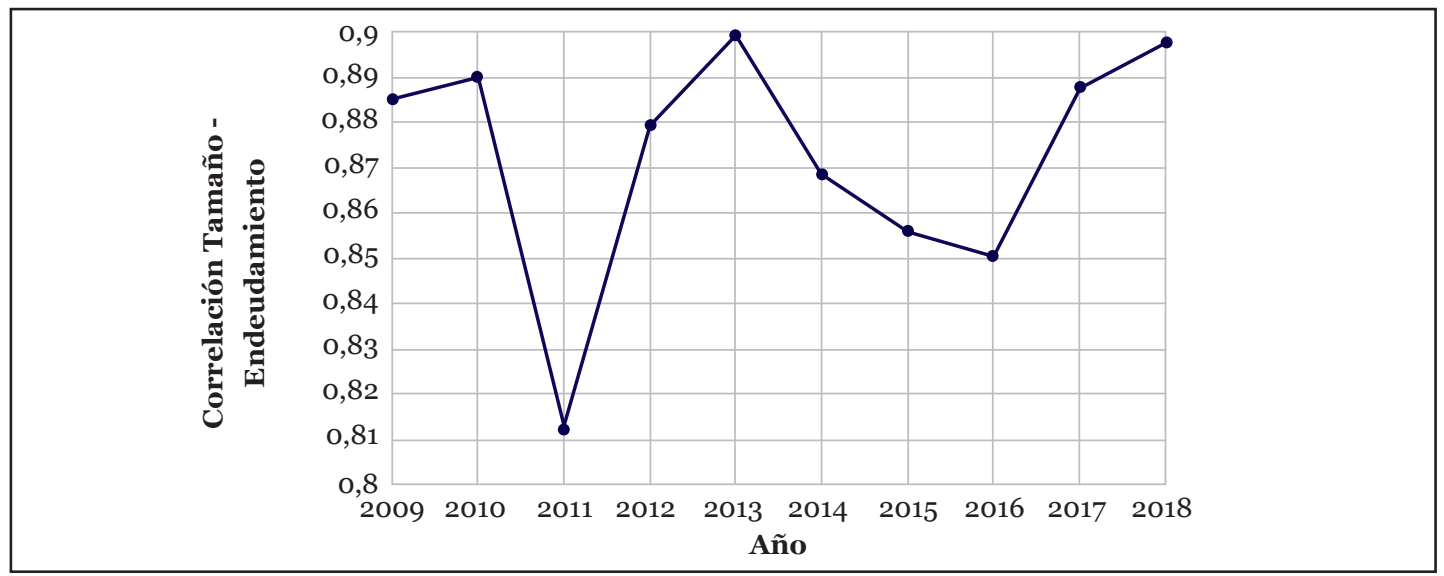

Fuente: Elaboración propia, (2018).

Siguiendo la interpretación de la tabla de correlaciones, al vincular el Tamaño y el Ciclo Operativo de las firmas, se observa una correlación con dirección negativa media en el período de estudio, i.e. 2009-2018. Como se expone en el gráfico 6, el indicador de correlación para el año 2018 alcanza su valor más acentuado aproximándose a -o,60 lo que representa en este año una correlación negativa considerable. El indicador más débil se encuentra entre los años 2011 y 2013 (aproximadamente -0,35). En promedio, para tal rango temporal bajo análisis, se tiene un índice de Pearson de -0,43. Esto significa, para todos los años, que existe una dependencia o correlación estocástica con tendencia media inversa, puesto que al incrementarse el Tamaño de la firma, lo contrario sucede con el Ciclo Operativo. En otras palabras, las empresas de mayor Tamaño poseen un Ciclo Operativo más corto, esto se logra con mayor Rotación de Inventarios y mayor Rotación de Cuentas a Cobrar con lo cual la empresa obtendría líquidos (conversión de Cuentas a Cobrar) en menor tiempo para de esta forma financiarse. Para este caso el nivel de significancia bilateral es $\mathrm{p}<1 \%$, lo que representa que la correlación es estadísticamente significativa, i.e. el riesgo de concluir que existe una correlación media inversa, cuando en realidad no es así, es menor al 1\%.

Gráfico 6. Correlación Tamaño-Ciclo Operativo. Período 2009-2018.

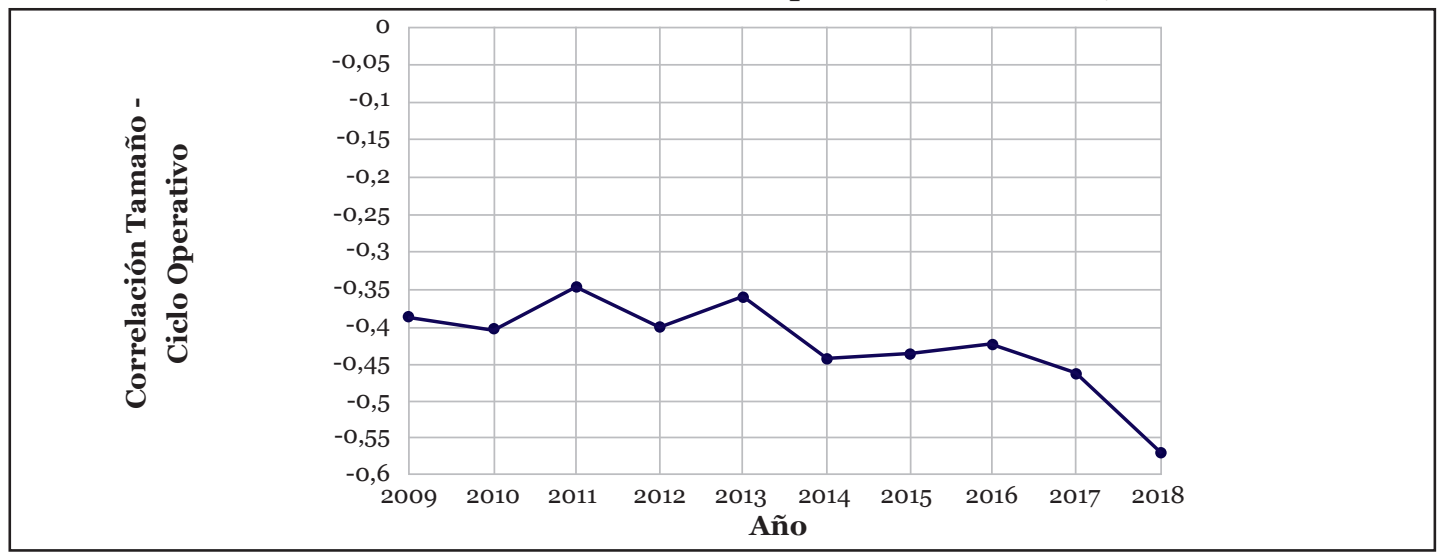

Fuente: Elaboración propia, (2018). 
$\mathrm{Al}$ relacionar el Endeudamiento y el Ciclo Operativo de las firmas, se observa una correlación con dirección negativa e intensidad débil a media en el período de estudio, i.e. 2009-2018. Como muestra el gráfico que a continuación se expone (Gráfico 7), el indicador de correlación para el año 2018 alcanza su valor más acentuado aproximándose a -0,45 lo que representa en este año una correlación negativa de intensidad media. El indicador más débil se ubica en el año 2016 (aproximadamente -0,12). En promedio, para tal rango de tiempo bajo estudio, se obtiene un índice de correlación de Pearson de -0,28. Esto significa, que existe una dependencia o correlación estocástica de intensidad débil a media e inversa, puesto que al incrementarse el Endeudamiento de la firma, lo contrario sucede con el Ciclo Operativo. Las firmas con mayor grado de Endeudamiento poseen Ciclos Operativos más cortos (menor tiempo de conversión de inventarios y cuentas a cobrar), pero se reitera que la correlación es de intensidad débil a media. En cuanto al nivel de significancia bilateral, al misma es de $\mathrm{p}<1 \%$, lo que representa que la correlación es estadísticamente significativa, i.e. el riesgo de concluir que existe una correlación débil inversa, cuando en realidad no es así, es menor al $1 \%$.

Gráfico 7. Correlación Endeudamiento-Ciclo Operativo. Período 2009-2018.

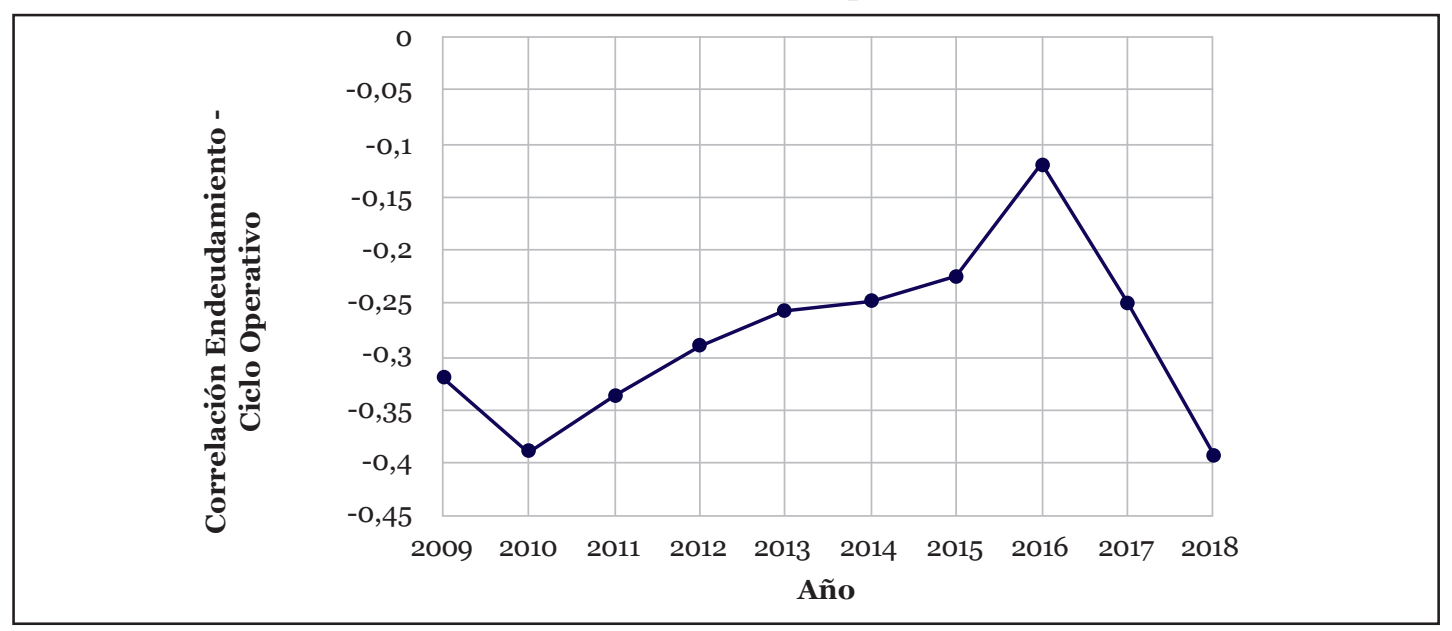

Fuente: Elaboración propia, (2018).

Para la correlación bivariada entre el Desempeño o Performance Empresaria $\left(\mathrm{Q}_{\mathrm{i}, \mathrm{t}}\right)$ y Ciclo Financiero (NTC) se muestra una correspondencia positiva que toma mayor intensidad en los años 2009-2012 (Gráfico 8). A partir de 2013 esta intensidad disminuye por lo que se da una vinculación débil, en un diagrama de dispersión de datos se represaría mediante una nube de puntos. Luego en 2018 tal intensidad aumenta pero se ubica siempre en el tramo de intensidad débil. El promedio general para el indicador de Pearson, en el rango temporal bajo estudio es de 0.25 . Existe para esta correlación un nivel de significancia bilateral de $\mathrm{p}<5 \%$. 
Gráfico 8. Correlación Desempeño o Performance Empresaria $\left(Q_{\mathrm{i}, \mathrm{t}}\right)$ y Ciclo Financiero (NTC). Período 2009-2018.

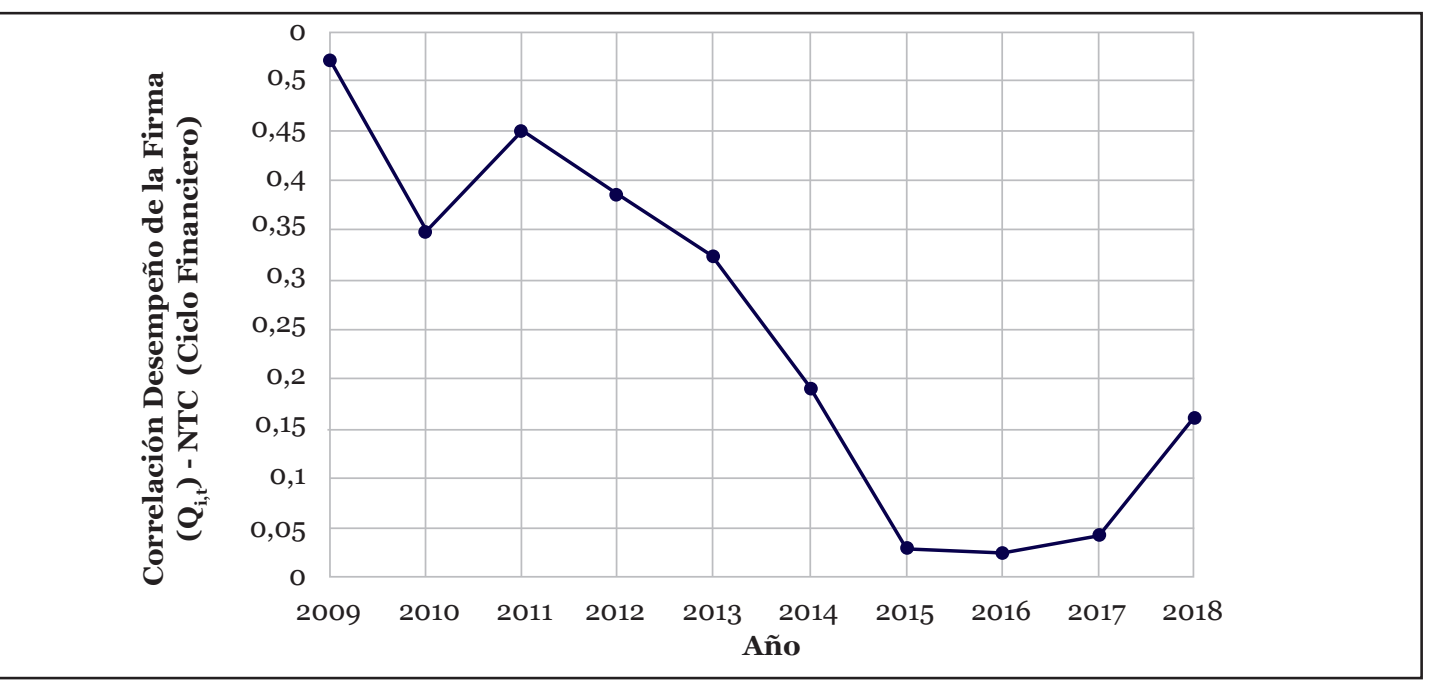

Fuente: Elaboración propia, (2018).

Para el caso de la relación entre el Ciclo Financiero (NTC) y las Probabilidades de Insolvencia de la firma tomando como horizonte temporal 10 años, $p(n=10)$, se observa una correlación con dirección negativa en todos los años bajo investigación. En cuanto a la intensidad, la relación inversa tiene tendencia entre débil y media, lo que significa que si el Ciclo Financiero se incrementa, la probabilidad de Insolvencia tiene un comportamiento contrario, reiterando que esta relación tiene intensidad débil/media. El Gráfico (Gráfico 9) muestra que en 2012 y 2016 se registran los valores negativos más acentuados del indicador de Pearson, alcanzando una correlación negativa entre el rango -0,40 y -0,45 aproximadamente. En 2013 arroja una correlación con indicador más cercano a cero, mostrando una correlación negativa débil. El promedio para todo el período bajo análisis es de -0,31 (indicador de correlación de Pearson). Existe para esta correlación un nivel de significancia bilateral de $\mathrm{p}<5 \%$.

Gráfico 9. Correlación Ciclo Financiero (NTC) y Probabilidades de Insolvencia. Período 2009-2018.

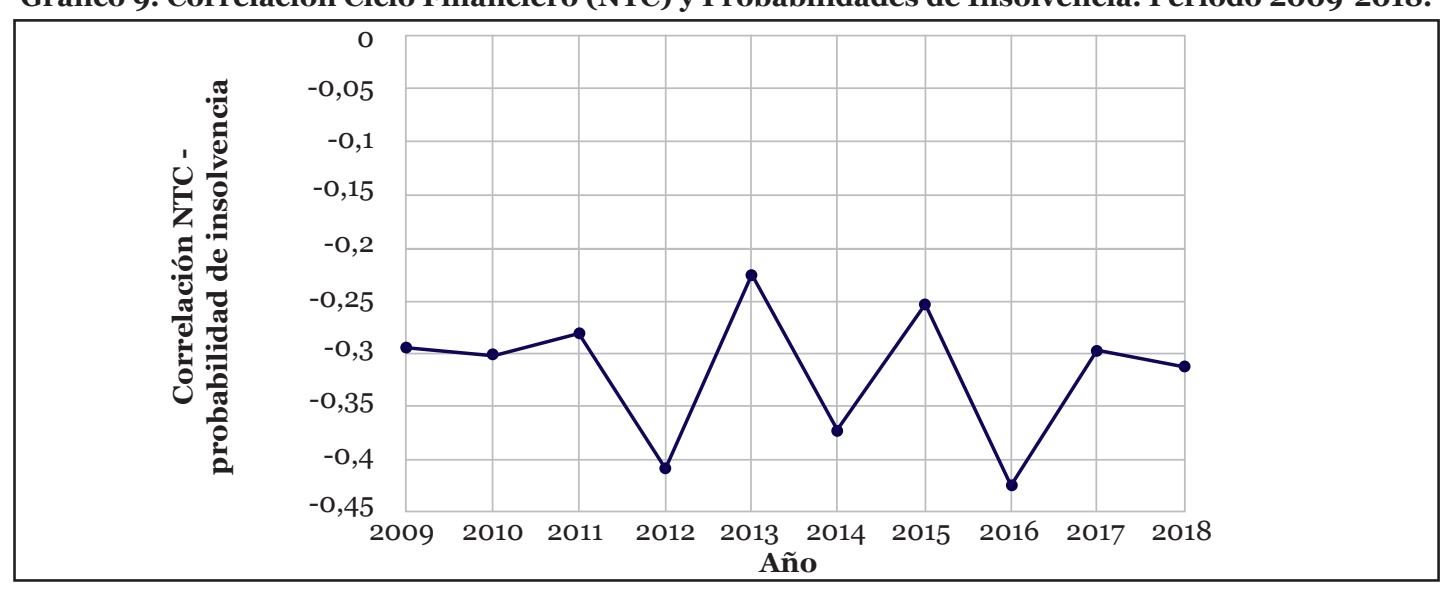

Fuente: Elaboración propia, (2018). 
Finalmente, los resultados de la vinculación entre ROA y las Probabilidades de Insolvencia muestran que existe una fuerte vinculación negativa, esto es así dado que el concepto y la formulación de la probabilidad de insolvencia (p) se nutre del indicador ROA. Cuanto mayor sea el coeficiente ROA, menor será la probabilidad de insolvencia. En promedio la correlación de Pearson arroja un indicador de -0,76. En esta prueba correlacional bivariada se obtiene un alto nivel de significancia bilateral de $\mathrm{p}<1 \%$, lo que representa que la correlación es estadísticamente significativa, i.e. el riesgo de concluir que existe una correlación negativa fuerte cuando en realidad no es así, es menor al $1 \%$.

\section{CONCLUSIONES}

Se puede observar a través de los resultados que brinda la estadística descriptiva comparativa para las carteras conformadas, que aquellas que se ubican con un tamaño superior al promedio, presentan un desempeño empresario más elevado, un menor ciclo financiero y operativo y un mayor crecimiento y ROA, con menor probabilidad de insolvencia. Por el contrario, aquellas firmas que se sitúan por debajo del tamaño promedio, muestran un desempeño empresario más bajo, un mayor ciclo financiero y operativo y un menor crecimiento y ROA, con mayor probabilidad de insolvencia. Del mismo modo ocurre para empresas que se colocan por encima del nivel de endeudamiento promedio, aquellas compañías que muestran un endeudamiento superior registran un desempeño empresario más alto, un menor ciclo financiero y operativo y un mayor crecimiento y nivel del indicador ROA, con menor probabilidad de fracaso financiero, aun cuando son las más endeudadas. Esta última situación se debe a que si bien estas empresas presentan mayor nivel de deuda, las mismas muestran también un mayor nivel de crecimiento y de ROA. Contrariamente, para las firmas que se ubican con un endeudamiento inferior al promedio, revelan un desempeño empresario más pequeño, un mayor ciclo financiero y operativo y un menor crecimiento y ROA, con mayor probabilidad de insolvencia dado este menor indicador ROA.

Por otra parte, de acuerdo a las correlaciones bivariadas realizadas, se pude visualizar una correlación positiva fuerte entre los vectores de clasificación de carteras, i.e., Tamaño y Endeudamiento. De los resultados a los cuales se ha llegado en el presente trabajo, se demuestra que para las empresas argentinas cotizantes en bolsa correspondientes a la unidad de análisis descripta por el período 2009-2018, aquellas compañías que poseen un mayor tamaño tienen también un mayor grado de endeudamiento. Esto es posible porque estas firmas logran mayor capacidad para absorber deuda en el mercado y financiarse. Se presentan asimismo otras vinculaciones relevantes para destacar, entre Tamaño y Ciclo Operativo se muestra una correlación inversa media para empresas cotizantes argentinas, en el período de estudio, i.e. 
2009-2018. Al aumentar el tamaño de la firma, lo contrario sucedería con el Ciclo Operativo, las empresas de mayor tamaño poseen un Ciclo Operativo más breve, a través de una mayor Rotación de Inventarios y mayor Rotación de Cuentas a Cobrar, motivo por el cual la firma generaría la liquidez necesaria en un menor tiempo para de esta forma financiarse. Asimismo, en cuanto al Endeudamiento y el Ciclo Operativo de las firmas, se observó una correlación inversa media para el período de estudio. Las firmas con mayor grado de endeudamiento poseen ciclos operativos más cortos, con menor tiempo de conversión de inventarios y menor tiempo de conversión en cuentas a cobrar.

Para el caso de la relación entre el Ciclo Financiero (NTC) y la Probabilidad de Insolvencia de la firma tomando como horizonte temporal 10 años, $\mathrm{p}(\mathrm{n}=10)$, se muestra para las empresas argentinas cotizantes en bolsa durante 2009-2018, una correlación media con dirección negativa en todos los años bajo investigación. Esto representa que ante un Ciclo Financiero más extenso, la probabilidad de default tenderá a disminuir, con una intensidad media. Continuando con el análisis de la probabilidad de insolvencia con respecto a otras variables, los resultados revelan que existe una fuerte correspondencia negativa fuerte entre el índice ROA y la Probabilidad de Insolvencia, esto es así por motivo de que el concepto y la formulación de la probabilidad de insolvencia (p) se nutre del indicador ROA. Cuanto mayor sea el coeficiente ROA, menor será la probabilidad de insolvencia.

Estas correlaciones son las más significativas del estudio realizado y sirven para caracterizar y describir a la unidad de análisis en cuestión. Se realizará posteriormente una investigación sobre la interferencia de las variables aquí trabajadas, en un modelo de regresión no lineal.

\section{REFERENCIAS BIBLIOGRÁFICAS}

AFZA, T. \& Nazir, M. S. (2007). Is it better to be aggressive or conservative in man-aging working Capital? Paper presented at Singapore Economic Review Conference (SERC) on August 02-04, Singapore.

Akinlo, O. O. (2010). The effect of Working Capital on profitability of firms in Nigeria. Evidence from General Method of Moments. Asian Journal of Business and Management Sciences, 1(2), pp. 130-135.

Baños-Caballero, S., García-Teruel, P., \& Martínez-Solano, P. (2012). How does working capital management affect the profitability of Spanish SMEs? Small Business Economics, 39(2), pp. 517-529. 


MARÍA ALICIA SCHIMDT |GASTÓN MILANESI
$58<\quad$ GESTIÓN DEL CAPITAL DE TRABAJO: ANÁLISIS DESCRIPTIVO Y CORRELACIONAL...
Págs. 43 - 63. DOI: $h$ ttp: $/ / d x$.doi.org/10.30972/rfce.2213948

Baños-Caballero, S., García-Teruel, P., \& Martínez-Solano, P. (2014). Working capital management, corporate performance, and financial constraints. Journal of Business Research 67(3), pp. 332-338.

Bharath, S \& Shumway, T. (2008). Forescasting Default with the Merton distance to default model. Review of Financial Studies, 23, pp. 589-609.

Deloof, M. (2003). Does Working Capital Management Affect Performance of Belgian Firms? Journal of Business, Finance and Accounting, 3o(3), pp. 573-587.

Faulkender, M. \& WANG, R. (2006). Corporate financial policy and the value of cash. Journal of Finance, 61(4), pp. 1957-1990.

García-Teruel, P.J \& Martínez-Solano, P. (2007). Effects of Working Capital Management on SME Performance. International Journal of Managerial Finance, 3(2), pp. 164-177.

Gill, A., Biger, N., \& Mathur, N. (2010). The relationship between working capital management and performance: evidence from the United States. Business and Economics Journal, 1O(2), pp. 1-9.

Hernández Sampieri, R., Fernandéz Collado, C., \& Baptista Lucio, M. (2014). Metodología de la Investigación. 6ta. Edición. México: McGraw Hill.

Jose, M. L., Lancaster, C., \& Stevens, J. L. (1996). Corporate returns and cash conversion cycles. Journal of Economics and Finance, 20 (1), pp. 33-46.

Kieschnick, R., Laplante, M., \& Moussawi, R. (2013). Working capital management and shareholder wealth. Review of Finance, 17(5), pp. 1827-1852.

Lazaridis, I. \& Tryfonidis, D. (2006). Relationship between Working Capital Management and Profitability of Listed Companies in the Athens Stock Exchange. Journal of Financial Management and Analysis 19(1), pp.26-59.

Nobanee, H. \& Alhajjar, M. (2009). Working capital management and firm's performance: An optimal cash conversion cycle. Retrieved 02/11/2018.

Nobanee, H. \& Alhajjar, M. (2014). An Optimal Cash Conversion Cycle. International Research Journal of Finance and Economics. March (120), pp. 13-22. 
Padachi, K. (2006). Trends in Working Capital Management and its Impact on Firms' Performance: An Analysis of Mauritian Small Manufacturing Firms. International Review of Business Research Papers, 2(2), pp. 45-58.

Raheman, A. \& Nasr, M. (2007). Working capital management and performance - case of Pakistani firms. International Review of Business Research Papers, 3(1), pp. 279-300.

Shin, H. H. \& Soenen, L. (1998). Efficiency of working capital and corporate profitability. Financial Practice \& Education, 8(2), pp. 37-45.

Smith, K. (1980). Profitability versus Liquidity Tradeoffs in Working Capital Management, in Readings on the Management of Working Capital, 2nd Edition. St. Paul: West Publishing Company, pp. 549-562.

Wang, Y. J. (2002). Liquidity management, operating performance, and corporate value: Evidence from Japan and Taiwan. Journal of Multinational Financial Management, 12(2), pp. 159-169.

\section{FUENTES CONSULTADAS}

Instituto Argentino de Mercado de Capitales. Sitio web institucional:

https://www.iamc.com.ar/home/

Comisión Nacional de Valores (CNV). Sitio web institucional:

https://www.cnv.gov.ar/SitioWeb/Empresas

Bolsar(C) Sitio web institucional:

https://www.bolsar.com/VistasDL/PaginaPrincipal.aspx

\section{COMO CITAR ESTE ARTÍCULO}

SCHMIDT, María Alicia y MILANESI, Gastón Arturo Ronald. Gestión del capital de trabajo: Análisis descriptivo y correlacional para empresas argentina cotizantes en bolsa. Revista de la Facultad de Ciencias Económicas - UNNE, Argentina. Volumen 22, Núm. 1, enero-junio 2019, ISSN 1668 - 6365. Págs. 43 - 63. DOI: http://dx.doi.org/10.30972/rfce.2213948 


\section{CURRICULUM VITAE}

\section{María Alicia Schmidt}

Especialista en Costos y Gestión Empresarial. Asistente de Docencia del Departamento de Ciencias de la Administración de la Universidad Nacional del Sur, Argentina.

alicia.schmidt@uns.edu.ar

\section{Gastón Arturo Ronald Milanesi}

Doctor en Ciencias de la Administración. Profesor Titular del Departamento de Ciencias de la Administración de la Universidad Nacional del Sur, Argentina.

milanesi@uns.edu.ar 


\section{ANEXO}

\begin{tabular}{|c|c|c|c|c|c|c|c|c|}
\hline 2018 & Tamaño & Endeud. & $Q i, t$ & NTC & $\begin{array}{l}\text { Ciclo } \\
\text { Operativo }\end{array}$ & GROWTH & $\boldsymbol{R O A}$ & $p(n=10)$ \\
\hline Tamaño & 1,000 & & & & & & & \\
\hline Endeudamiento & o,898 & 1,000 & & & & & & \\
\hline Q i,t & $-0,275$ & $-0,296$ & 1,000 & & & & & \\
\hline NTC & $-0,298$ & $-0,192$ & 0,161 & 1,000 & & & & \\
\hline Ciclo Operativo & $-0,568$ & $-0,391$ & 0,230 & 0,762 & 1,000 & & & \\
\hline GROWTH & 0,395 & 0,400 & $-0,270$ & $-0,080$ & $-0,171$ & 1,000 & & \\
\hline $\mathrm{ROA}$ & 0,254 & 0,241 & $-0,246$ & 0,337 & 0,108 & 0,062 & 1,000 & \\
\hline $\mathrm{p}(\mathrm{n}=10)$ & $-0,169$ & $-0,164$ & $-0,021$ & $-0,312$ & $-0,144$ & 0,057 & $-0,701$ & 1,000 \\
\hline 2017 & Tamaño & Endeud. & $Q i, t$ & NTC & $\begin{array}{l}\text { Ciclo } \\
\text { Operativo }\end{array}$ & GROWTH & $\boldsymbol{R O A}$ & $p(n=10)$ \\
\hline Tamaño & 1,000 & & & & & & & \\
\hline Endeudamiento & $\mathbf{0 , 8 8 8}$ & 1,000 & & & & & & \\
\hline Q i,t & $-0,097$ & $-0,152$ & 1,000 & & & & & \\
\hline NTC & $-0,249$ & $-0,148$ & 0,043 & 1,000 & & & & \\
\hline Ciclo Operativo & $-0,464$ & $-0,249$ & 0,074 & 0,740 & 1,000 & & & \\
\hline GROWTH & 0,135 & 0,109 & $-0,018$ & $-0,107$ & $-0,220$ & 1,000 & & \\
\hline ROA & 0,173 & o,091 & 0,382 & 0,208 & 0,069 & $-0,108$ & 1,000 & \\
\hline $\mathrm{p}(\mathrm{n}=10)$ & $-0,159$ & $-0,125$ & $-0,290$ & $-0,295$ & $-0,168$ & 0,097 & $-0,855$ & 1,000 \\
\hline 2016 & Tamaño & Endeud. & $Q i, t$ & NTC & $\begin{array}{l}\text { Ciclo } \\
\text { Operativo }\end{array}$ & GROWTH & $\boldsymbol{R O A}$ & $p(n=10)$ \\
\hline Tamaño & 1,000 & & & & & & & \\
\hline Endeudamiento & $\mathbf{0 , 8 5 1}$ & 1,000 & & & & & & \\
\hline $\mathrm{Q} i, \mathrm{t}$ & $-0,062$ & $-0,124$ & 1,000 & & & & & \\
\hline NTC & $-0,274$ & $-0,152$ & 0,025 & 1,000 & & & & \\
\hline Ciclo Operativo & $-0,424$ & $-0,120$ & $-0,080$ & 0,792 & 1,000 & & & \\
\hline GROWTH & 0,112 & 0,046 & 0,309 & $-0,082$ & $-0,164$ & 1,000 & & \\
\hline $\mathrm{ROA}$ & $-0,003$ & $-0,137$ & 0,182 & 0,190 & $-0,043$ & 0,198 & 1,000 & \\
\hline $\mathrm{p}(\mathrm{n}=10)$ & 0,057 & 0,158 & $-0,201$ & $-0,424$ & $-0,176$ & $-0,065$ & $-0,812$ & 1,000 \\
\hline 2015 & Tamaño & Endeud. & $Q i, t$ & NTC & $\begin{array}{l}\text { Ciclo } \\
\text { Operativo }\end{array}$ & GROWTH & $\boldsymbol{R O A}$ & $p(n=10)$ \\
\hline Tamaño & 1,000 & & & & & & & \\
\hline Endeudamiento & 0,856 & 1,000 & & & & & & \\
\hline Q i,t & o,090 & 0,169 & 1,000 & & & & & \\
\hline NTC & $-0,241$ & $-0,262$ & o,030 & 1,000 & & & & \\
\hline Ciclo Operativo & $-0,437$ & $-0,224$ & 0,107 & 0,745 & 1,000 & & & \\
\hline GROWTH & 0,125 & 0,107 & 0,070 & $-0,059$ & $-0,183$ & 1,000 & & \\
\hline $\mathrm{ROA}$ & 0,123 & $-0,083$ & 0,017 & 0,219 & $-0,074$ & 0,009 & 1,000 & \\
\hline $\mathrm{p}(\mathrm{n}=10)$ & $-0,262$ & $-0,163$ & o,033 & $-0,254$ & $-0,051$ & $-0,109$ & $-0,772$ & 1,000 \\
\hline
\end{tabular}




\begin{tabular}{|c|c|c|c|c|c|c|c|c|}
\hline 2014 & Tamaño & Endeud. & $Q i, t$ & NTC & $\begin{array}{l}\text { Ciclo } \\
\text { Operativo }\end{array}$ & GROWTH & $\boldsymbol{R O A}$ & $p(n=10)$ \\
\hline Tamaño & 1,000 & & & & & & & \\
\hline Endeudamiento & 0,868 & 1,000 & & & & & & \\
\hline Q i,t & 0,111 & 0,208 & 1,000 & & & & & \\
\hline NTC & $-0,307$ & $-0,294$ & 0,191 & 1,000 & & & & \\
\hline Ciclo Operativo & $-0,443$ & $-0,246$ & 0,366 & 0,797 & 1,000 & & & \\
\hline GROWTH & 0,102 & 0,109 & $-0,027$ & $-0,105$ & $-0,215$ & 1,000 & & \\
\hline ROA & 0,146 & 0,042 & $-0,066$ & 0,270 & $-0,020$ & 0,113 & 1,000 & \\
\hline $\mathrm{p}(\mathrm{n}=10)$ & $-0,140$ & $-0,019$ & $-0,025$ & $-0,372$ & $-0,043$ & $-0,127$ & $-0,811$ & 1,000 \\
\hline 2013 & Tamaño & Endeud. & $Q i, t$ & NTC & $\begin{array}{l}\text { Ciclo } \\
\text { Operativo }\end{array}$ & GROWTH & $\boldsymbol{R O A}$ & $p(n=10)$ \\
\hline Tamaño & 1,000 & & & & & & & \\
\hline Endeudamiento & 0,899 & 1,000 & & & & & & \\
\hline Q i,t & 0,230 & 0,158 & 1,000 & & & & & \\
\hline NTC & $-0,279$ & $-0,293$ & 0,323 & 1,000 & & & & \\
\hline Ciclo Operativo & $-0,361$ & $-0,257$ & 0,314 & 0,882 & 1,000 & & & \\
\hline GROWTH & 0,115 & 0,127 & $-0,032$ & $-0,135$ & $-0,202$ & 1,000 & & \\
\hline ROA & 0,117 & 0,043 & $-0,047$ & 0,038 & $-0,037$ & 0,198 & 1,000 & \\
\hline $\mathrm{p}(\mathrm{n}=10)$ & 0,014 & 0,109 & $-0,026$ & $-0,225$ & $-0,155$ & $-0,141$ & $-0,807$ & 1,000 \\
\hline 2012 & Tamaño & Endeud. & $Q i, t$ & NTC & $\begin{array}{l}\text { Ciclo } \\
\text { Operativo }\end{array}$ & GROWTH & $\boldsymbol{R O A}$ & $p(n=10)$ \\
\hline Tamaño & 1,000 & & & & & & & \\
\hline Endeudamiento & $\mathbf{0 , 8 7 9}$ & 1,000 & & & & & & \\
\hline Q i,t & 0,134 & 0,026 & 1,000 & & & & & \\
\hline NTC & $-0,270$ & $-0,296$ & 0,386 & 1,000 & & & & \\
\hline Ciclo Operativo & $-0,400$ & $-0,290$ & 0,271 & 0,836 & 1,000 & & & \\
\hline GROWTH & 0,095 & 0,139 & 0,026 & $-0,150$ & $-0,220$ & 1,000 & & \\
\hline ROA & 0,036 & $-0,142$ & 0,279 & 0,308 & 0,007 & 0,214 & 1,000 & \\
\hline $\mathrm{p}(\mathrm{n}=10)$ & 0,041 & 0,182 & $-0,176$ & $-0,407$ & $-0,173$ & $-0,169$ & $-0,800$ & 1,000 \\
\hline 2011 & Tamaño & Endeud. & $Q i, t$ & NTC & $\begin{array}{l}\text { Ciclo } \\
\text { Operativo }\end{array}$ & GROWTH & $\boldsymbol{R O A}$ & $p(n=10)$ \\
\hline Tamaño & 1,000 & & & & & & & \\
\hline Endeudamiento & $\mathbf{0 , 8 1 3}$ & 1,000 & & & & & & \\
\hline Q i,t & 0,076 & $-0,056$ & 1,000 & & & & & \\
\hline NTC & $-0,109$ & $-0,358$ & 0,450 & 1,000 & & & & \\
\hline Ciclo Operativo & $-0,348$ & $-0,335$ & 0,309 & 0,742 & 1,000 & & & \\
\hline GROWTH & 0,071 & 0,164 & $-0,082$ & $-0,157$ & $-0,214$ & 1,000 & & \\
\hline ROA & 0,113 & $-0,136$ & 0,337 & 0,231 & $-0,040$ & o,o39 & 1,000 & \\
\hline $\mathrm{p}(\mathrm{n}=10)$ & 0,116 & 0,263 & $-0,255$ & $-0,280$ & $-0,166$ & $-0,107$ & $-0,704$ & 1,000 \\
\hline
\end{tabular}




\begin{tabular}{|c|c|c|c|c|c|c|c|c|}
\hline 2010 & Tamaño & Endeud. & $Q i, t$ & NTC & $\begin{array}{l}\text { Ciclo } \\
\text { Operativo }\end{array}$ & GROWTH & $\boldsymbol{R O A}$ & $p(n=10)$ \\
\hline Tamaño & 1,000 & & & & & & & \\
\hline Endeudamiento & $\mathbf{0 , 8 9 0}$ & 1,000 & & & & & & \\
\hline Q i,t & 0,040 & 0,045 & 1,000 & & & & & \\
\hline NTC & $-0,391$ & $-0,426$ & 0,348 & 1,000 & & & & \\
\hline Ciclo Operativo & $-0,404$ & $-0,389$ & 0,411 & 0,855 & 1,000 & & & \\
\hline GROWTH & 0,090 & 0,190 & $-0,065$ & $-0,159$ & $-0,201$ & 1,000 & & \\
\hline ROA & 0,172 & $-0,009$ & 0,241 & 0,166 & 0,009 & $-0,021$ & 1,000 & \\
\hline $\mathrm{p}(\mathrm{n}=10)$ & $-0,041$ & 0,107 & $-0,234$ & $-0,301$ & $-0,208$ & $-0,069$ & $-0,677$ & 1,000 \\
\hline 2009 & Tamaño & Endeud. & $Q i, t$ & NTC & $\begin{array}{l}\text { Ciclo } \\
\text { Operativo }\end{array}$ & GROWTH & $\boldsymbol{R O A}$ & $p(n=10)$ \\
\hline Tamaño & 1,000 & & & & & & & \\
\hline Endeudamiento & $\mathbf{0 , 8 8 5}$ & 1,000 & & & & & & \\
\hline Q i,t & 0,028 & 0,041 & 1,000 & & & & & \\
\hline NTC & $-0,283$ & $-0,315$ & 0,522 & 1,000 & & & & \\
\hline Ciclo Operativo & $-0,388$ & $-0,319$ & 0,581 & 0,827 & 1,000 & & & \\
\hline GROWTH & 0,158 & 0,183 & $-0,029$ & $-0,095$ & $-0,153$ & 1,000 & & \\
\hline ROA & 0,161 & 0,030 & 0,081 & 0,126 & $-0,028$ & 0,020 & 1,000 & \\
\hline $\mathrm{p}(\mathrm{n}=10)$ & $-0,011$ & 0,042 & $-0,153$ & $-0,294$ & $-0,244$ & $-0,035$ & $-0,644$ & 1,000 \\
\hline
\end{tabular}

Fuete: elaboración propia, (2019). 